\title{
Analysis of the Nozzle Hole Diameter Effect to Common Rail Diesel Engine Characteristics using a Calculated Model of an Internal Combustion Engine
}

\author{
Andrey Y. Dunin ${ }^{1}$, Nguyen Thin Quynh ${ }^{2}$, Mikhail G. Shatrov ${ }^{3}$, Leonid N. Golubkov ${ }^{4}$ \\ ${ }^{1}$ Ishlinsky Institute for Problems in Mechanics RAS, Russia, a.u.dunin @ yandex.ru \\ ${ }^{2}$ Moscow Automobile and Road Construction State Technical University (MADI), Russia, thinquynh@ gmail.com \\ ${ }^{3}$ Ishlinsky Institute for Problems in Mechanics RAS, Russia, dvs@ madi.ru \\ ${ }^{4}$ Moscow Automobile and Road Construction State Technical University (MADI), Russia, \\ dvsgolubkov@yandex.ru
}

\begin{abstract}
The study presents the results of modeling a single-cylinder engine, which estimates the influence of the diameter of the nozzle hole $\left(d_{c}\right)$ for fuel injection on the performance of the diesel engine (indicator power $N_{i}$, break specific fuel consumption $g_{e}$ ) and gaseous emissions (soot, $\mathrm{NO}_{\mathrm{x}}, \mathrm{HC}, \mathrm{CO}$ ). 3D modeling was performed by means AVL Fire ESE Diesel. The results show that as $d_{c}$ increased, the average pressure and average temperature in the combustion chamber decreased. In addition, when $d_{c}$ increases from 0.1 to 0.24 $\mathrm{mm}, N_{i}$ increases by $3.6 \%, g_{e}$ decreases by $3.9 \%$. At the same time, the NOx value is reduced by $71.8 \%$, and the soot value is reduced by $63 \%$. In contrast, the $\mathrm{HC}$ value increases by $93.1 \%$ and the $\mathrm{CO}$ value increases by $76.7 \%$.
\end{abstract}

Key words : diesel engine; diameter of the nozzle hole; exhaust gas emission; combustion.

\section{INTRODUCTION}

Although diesel engines are widely used to power vehicles and construction vehicles, it still needs to improve thermal efficiency and reduce exhaust emissions. Over the years, diesel engines have been constantly developed and improved to meet increasingly stringent emission standards.

There are three groups of solutions that can be applied to reduce emissions: the design technology of the engine; exhaust gas cleaning technology; use of alternative fuel $[1,2$, $3,4,5]$ and additives for lubricants.

In addition, operating mode and control technologies have been an important role in reducing emissions and improving the efficiency of the engine and vehicle [6].
The design is directly related to the shape of the combustion chamber and the design of the nozzle $[7,8,9]$. The structure of the combustion chamber and the nozzle have a significant impact on combustion, exhaust gas generation, and fuel consumption. The structure of the combustion chamber and the nozzle have a significant impact on combustion, exhaust gases emissions, and fuel consumption. The structure of the nozzle and the diameter of the fuel injection nozzle $\left(d_{c}\right)$ are all the more significant for a heavy diesel engine with low turbulence, while the mixture in the combustion chamber is regulated by the fuel injection and the geometry of the piston head. In addition, the fuel injection pressure has a significant effect on the toxic content (soot, $\mathrm{NO}_{\mathrm{x}}, \mathrm{HC}, \mathrm{CO}$ ) of the exhaust gases.

When increasing the fuel injection pressure with other modifications, including optimized nozzle geometries, engine design and other engine advances, fuel efficiency could improve $4 \%[10,11]$. Increasing of injection pressure is the basic development trend of the common rail fuel system, which ensures multiple injection with the desired shape of the front edge of the basic injection rate [12,13] and organization of fuel distribution in the combustion chamber $[7,8]$.

The desired fuel injection law at any operation mode of the engine is formed by variation of the control impulse duration $[7,8,9]$ and pressure in the common rail. It also depends on wave phenomenon originating in the high-pressure line and affects considerably on the fuel injection process in case of a multistage injection $[14,15]$.

Increasing the injection pressure is accompanied by a reduction in the size of the nozzle tip. Joint selection of the nozzle design of the sprayer, injection pressure and combustion chamber parameters help to improve the specific fuel consumption by $4 \%$ [16].

This study shows the effect of $d_{c}$ on the characteristics of diesel engines with a common rail fuel system. 3D modeling was performed by means AVL Fire ESE Diesel [17]. 
Andrey Y. Dunin et al., International Journal of Emerging Trends in Engineering Research, 8(6), June 2020, 2301 - 2308

\section{SIMULATION MODEL}

\subsection{Combustion model - ECFM-3Z model}

The existing ECFM model is devoted to gasoline combustion. The ECFM-3Z model was developed by the GSM consortium (Groupement Scientifque Moteurs) specifically for Diesel combustion (Figure 1). This is a combustion model based on a flame surface density transport equation and a mixing model that can describe inhomogeneous turbulent premixed and diffusion combustion. The model relies on the ECFM combustion model, previously described and implemented in FIRE and on three areas mixing description. Further it is coupled with an improved burnt gas chemistry description compared to ECFM [17].

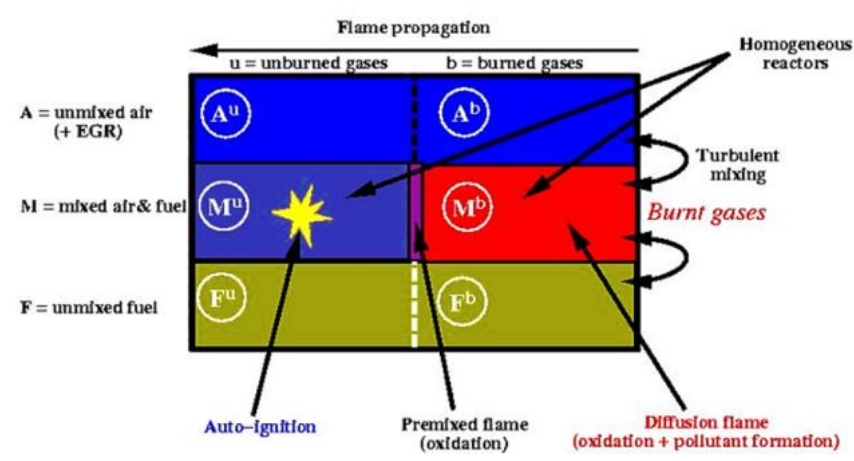

Figure 1: Zones in ECFM - 3Z model

\subsection{Pollutant modelling}

The mechanism calculates the formation the NO using the classical extended Zeldovich scheme as follows:

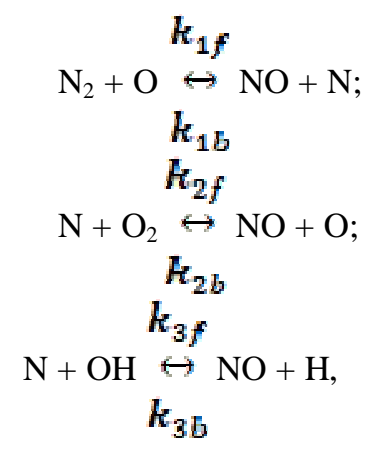

with the reaction rates $\omega_{N O}$, for each reaction $\mathrm{r}$ considering both formation and destruction of $\mathrm{NO}$, respectively.

The reaction rate $\omega_{i}$ of each participating species $i$ in the reaction $\mathrm{r}$ using the stoichiometric coefficients $v_{i, r}$ can be written as:

$$
\omega_{i}=\sum_{r=1}^{3} v_{i, r} \omega_{N o}
$$

It is assumed that species with low concentrations are in stationary state and that their mass fractions remain at their equilibrium values during the kinetic phase.

With soot, a kinetic model was applied.

\section{3 k-zeta-f turbulence model}

This model was developed by Hanjalic, Popovac and Hadziabdic (2004). The authors propose a version of the vortex viscosity model based on the concept of elliptical relaxation by Durbin (1991) [18]. The goal is to improve the numerical stability of the original $\overline{v^{2}}-f$ model by solving the transfer equation for the speed scale ratio $\zeta=\overline{v^{2}} / k$ instead of the speed scale $v^{2}$, the Full model is given below.

The vortex viscosity is obtained from

$$
\mathrm{v}_{\mathrm{t}}=\mathrm{c}_{\mu} \zeta \frac{\mathrm{k}^{2}}{\varepsilon}
$$

and the rest of the variables from the next set of the model equation, thus,

$$
\begin{gathered}
\rho \frac{D k}{D t}=\rho\left(P_{k}-\varepsilon\right)+\frac{\partial}{\partial \mathrm{x}_{j}}\left[\left(\mu+\frac{\mu_{t}}{\sigma_{k}}\right) \frac{\partial \mathrm{k}}{\partial \mathrm{x}_{j}}\right] \\
\rho \frac{D \varepsilon}{D t}=\rho \frac{\left(C_{\varepsilon 1}^{*} P_{k}-C_{\varepsilon 2} \varepsilon\right)}{T}+\frac{\partial}{\partial \mathrm{x}_{j}}\left[\left(\mu+\frac{\mu_{t}}{\sigma_{k}}\right) \frac{\partial \varepsilon}{\partial \mathrm{x}_{j}}\right] \\
\rho \frac{D \zeta}{D t}=\rho f-\rho \frac{\zeta}{k} P_{k}+\frac{\partial}{\partial \mathrm{x}_{j}}\left[\left(\mu+\frac{\mu_{t}}{\sigma_{l}}\right) \frac{\partial \zeta}{\partial \mathrm{x}_{j}}\right],
\end{gathered}
$$

where the following form of the equation $\mathrm{f}$ is accepted

$$
f-L^{2} \frac{\partial^{2} f}{\partial \mathrm{x}_{j} \partial \mathrm{x}_{j}}=\left(C_{1}+C_{2} \frac{F_{k}}{\zeta}\right) \frac{\frac{2}{3}-\zeta}{T}
$$

both the turbulent time scale $\mathrm{T}$ and the length scale $\mathrm{L}$ are defined as

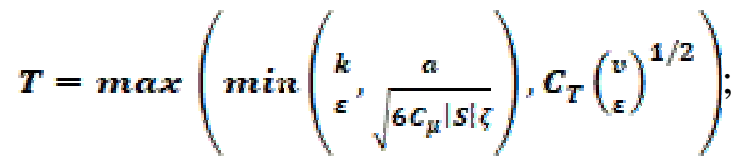

$$
\begin{aligned}
& L=C_{L} \max \left(\min \left(\frac{k^{3 / 2}}{s}, \frac{k^{1 / 2}}{\sqrt{6 C_{\mu}|s| \zeta}}\right), C_{\eta} \frac{v^{3 / 4}}{\varepsilon^{1 / 4}}\right) \\
& \rho \frac{D \zeta}{D t}=\rho f-\rho_{k}^{\zeta} \boldsymbol{P}_{k}+\frac{\partial}{\partial \mathrm{x}_{l}}\left[\left(\mu+\frac{\mu_{t}}{\sigma_{\zeta}}\right) \frac{\partial \zeta}{\partial \mathrm{x}_{\eta}}\right] \text {. }
\end{aligned}
$$

Additional modifications in the equation $\varepsilon$ are that the constant $C_{\varepsilon l}$ is damped near the wall, thus

$$
\mathrm{C}_{\mathrm{\varepsilon} 1}^{*}=\mathrm{C}_{\mathrm{\varepsilon} 1}(1+0.045 \sqrt{1 / \zeta})
$$


Andrey Y. Dunin et al., International Journal of Emerging Trends in Engineering Research, 8(6), June 2020, 2301 - 2308

This calculation is more reliable than the original $\overline{v^{2}}-\mathrm{f}$ model.

In addition, sub-models employed are shown in Table 1.

Table 1: AVL-FIRE sub-models

\begin{tabular}{|l|l|}
\hline Spray model & Wave \\
\hline Spray wall interaction model & Walljet1 \\
\hline Droplet Evaporation model & Dukowicz \\
\hline Turbulence model & k-zeta-f \\
\hline Ignition model & Auto - ignition \\
\hline NO formation & Extended Zeldovich \\
\hline Soot formation & Kinetic \\
\hline
\end{tabular}

The engine specifications for the model are shown in Table 2. The single-cylinder with a displacement of approximately 1.471 had a compression ratio of $15.4: 1$. The initial and boundary conditions are given in Table 3 .

Table 2: Engine Specifications

\begin{tabular}{|l|r|}
\hline Bore $D, \mathrm{~mm}$ & 120 \\
\hline Stroke $S, \mathrm{~mm}$ & 130 \\
\hline Connecting rod length, mm & 224 \\
\hline Number of cylinders & 1 \\
\hline Displacement volume, $l$ & 1.47 \\
\hline Compression ratio & 15.4 \\
\hline Number of valves & 4 \\
\hline Number of nozzle holes & 8 \\
\hline Nozzle hole diameter $d_{c}, \mathrm{~mm}$ & 0.24 \\
\hline
\end{tabular}

Table 3: Initial and boundary conditions

\begin{tabular}{|l|r|}
\hline Engine speed, rpm & 1400 \\
\hline Intake air temperature, K & 300 \\
\hline Intake air pressure, bar & 3.5 \\
\hline Cylinder head temperature, $\mathrm{K}$ & 550.15 \\
\hline Piston top temperature, $\mathrm{K}$ & 575.15 \\
\hline Fuel injection temperature, $\mathrm{K}$ & 330.15 \\
\hline Cylinder wall temperature, K & 475.15 \\
\hline Start of injection & $-17^{\circ}$ CA BTDC \\
\hline Spray angle & $160^{\circ}$ \\
\hline
\end{tabular}

The shape of the spray combustion chamber is shown in Figure 2,a. The computational modeling grid in the software is shown in Figure 2,b with a total of 57504 elements.

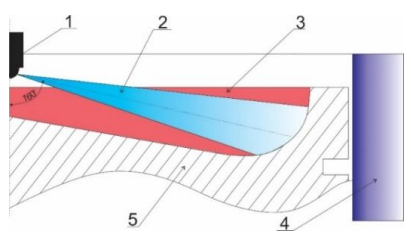

a

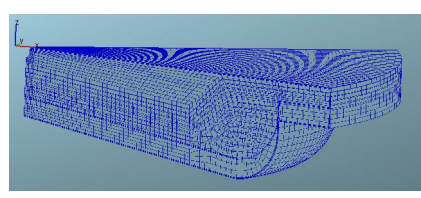

b
Figure 2: Geometry of combustion chamber: 1 - nozzle; $2-$ spray; 3 - combustion chamber; 4 - cylinder; 5 - piston
Figure 3 illustrates the fuel injection rate used in the model. The fuel injection rate was determined experimentally.

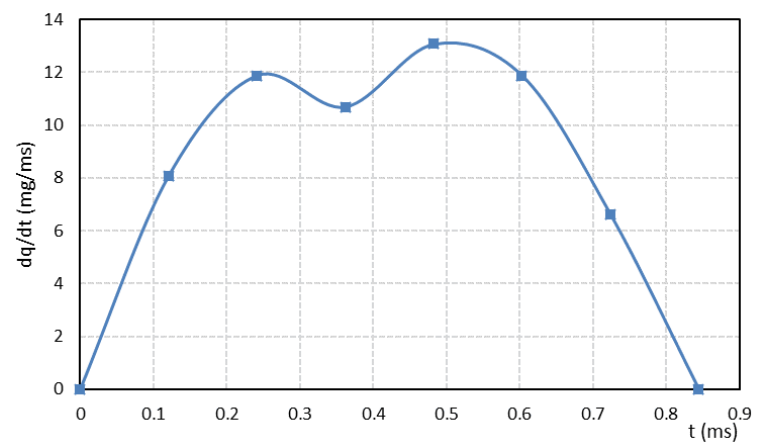

Figure 3: The fuel injection rate used in the model

\section{SIMULATION RESULTS}

Figure 4 and Figure 5 shows the change in the mean pressure, rate of heat release and mean temperature in the cylinder when $d_{c}$ has changed from 0.1 to $0.24 \mathrm{~mm}$, the boost pressure is $0.15 \mathrm{MPa}$, and the amount of fuel for each cycle is $60 \mathrm{mg}$.
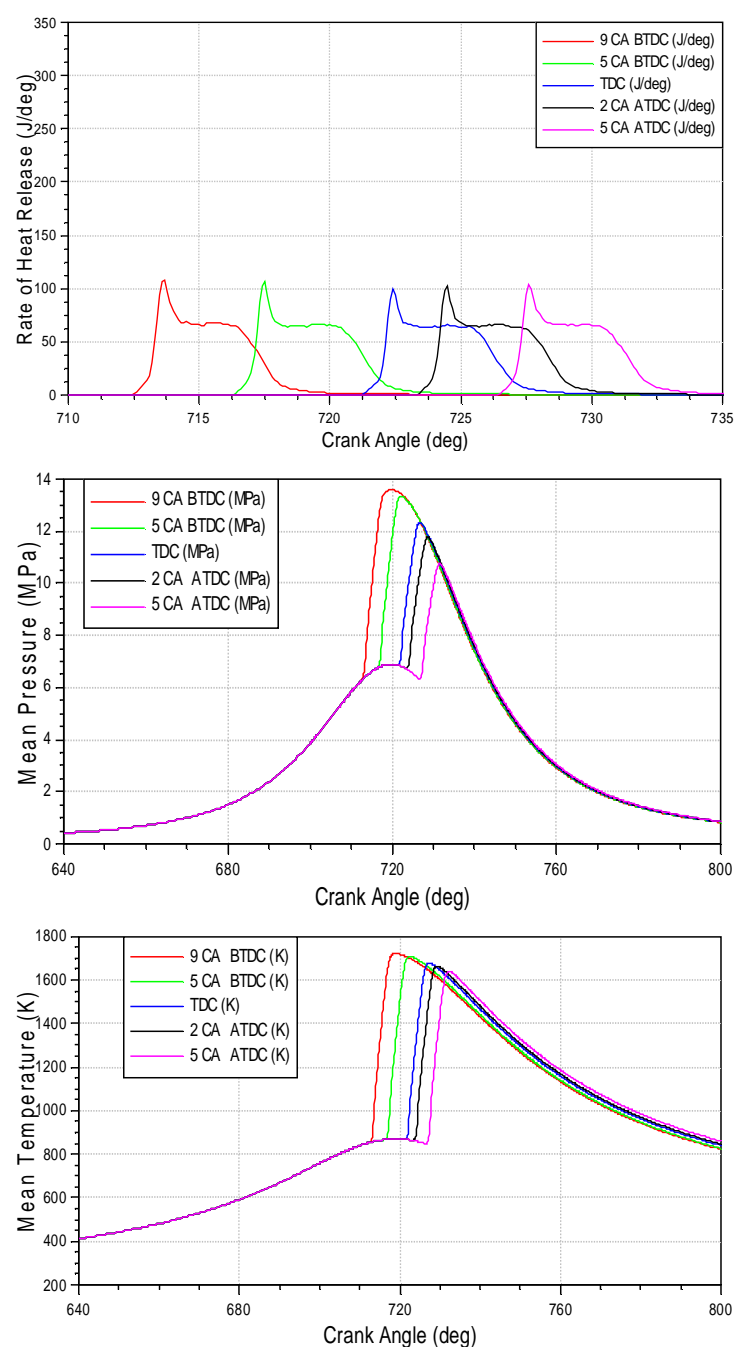

Figure 4: Comparison of combustion characteristics at a boost pressure of $0.15 \mathrm{MPa}\left(d_{c}=0.1 \mathrm{~mm}\right)$ 

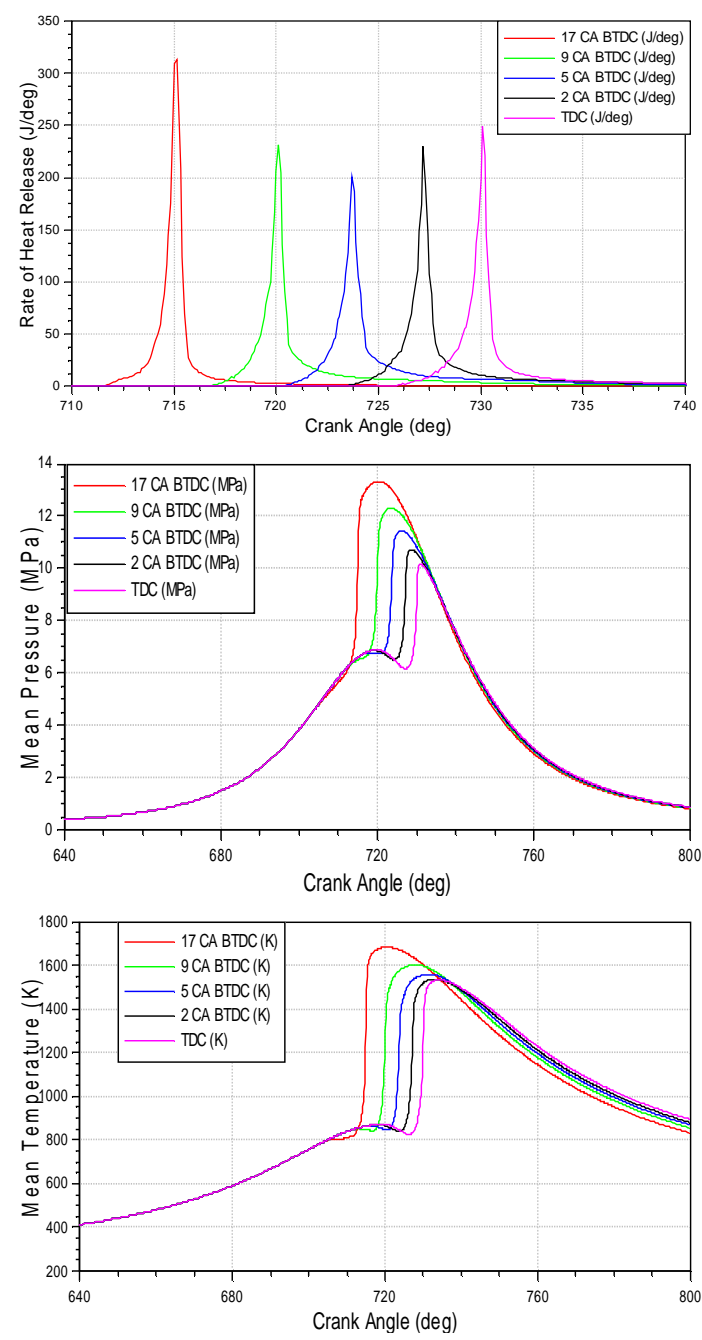

Figure 5: Comparison of combustion characteristics at a boost pressure of $0.15 \mathrm{MPa}\left(d_{c}=0.24 \mathrm{~mm}\right)$

It can be seen that with the same amount of fuel for the cycle, the smaller the diameter of the nozzle hole, the moment of fuel injection is adjusted to the TDC. The pressure in the cylinder is almost equal to the level at the best injection angle with a large bore diameter. With small holes for high-pressure fuel injection with a small drop size, the time for fuel evaporation is very short. The combustion process is fast, so the rate of heat release increases. However, the generated heat is then absorbed by the mixture in the combustion chamber. Therefore, combustion slows down, the rate of heat release decreases, and is maintained until the end of the fuel injection process. Then the rate of heat release gradually decreases until the end of the combustion process.

With $d_{c}=0,24 \mathrm{Mm}$ and injection from 17 CA BTDC of fuel, it takes time for evaporation to create a mixture. The maximum rate of heat release is when the piston is at 5 CA BTDC.

The reason is that when the fuel is fed too early, it evaporates under both compression and combustion conditions, so the rate of heat release increases very quickly. The engine does not produce maximum power. And if the fuel supply is late relative to the position of the piston in the TDC, the fuel cannot evaporate and form a mixture. Therefore, the rate of heat release is high, but the pressure in the combustion chamber drops sharply. HC emissions are increasing. The best fuel injection angle was 5 CA BTDC, the engine produces the highest power and the lowest fuel consumption. The temperature field in the combustion chamber observed using the CAD software is shown in Figure 6, Figure 7 and Figure 8 , Figure 9 . The injection angle is set to 5 CA BTDC and at the TDC position.

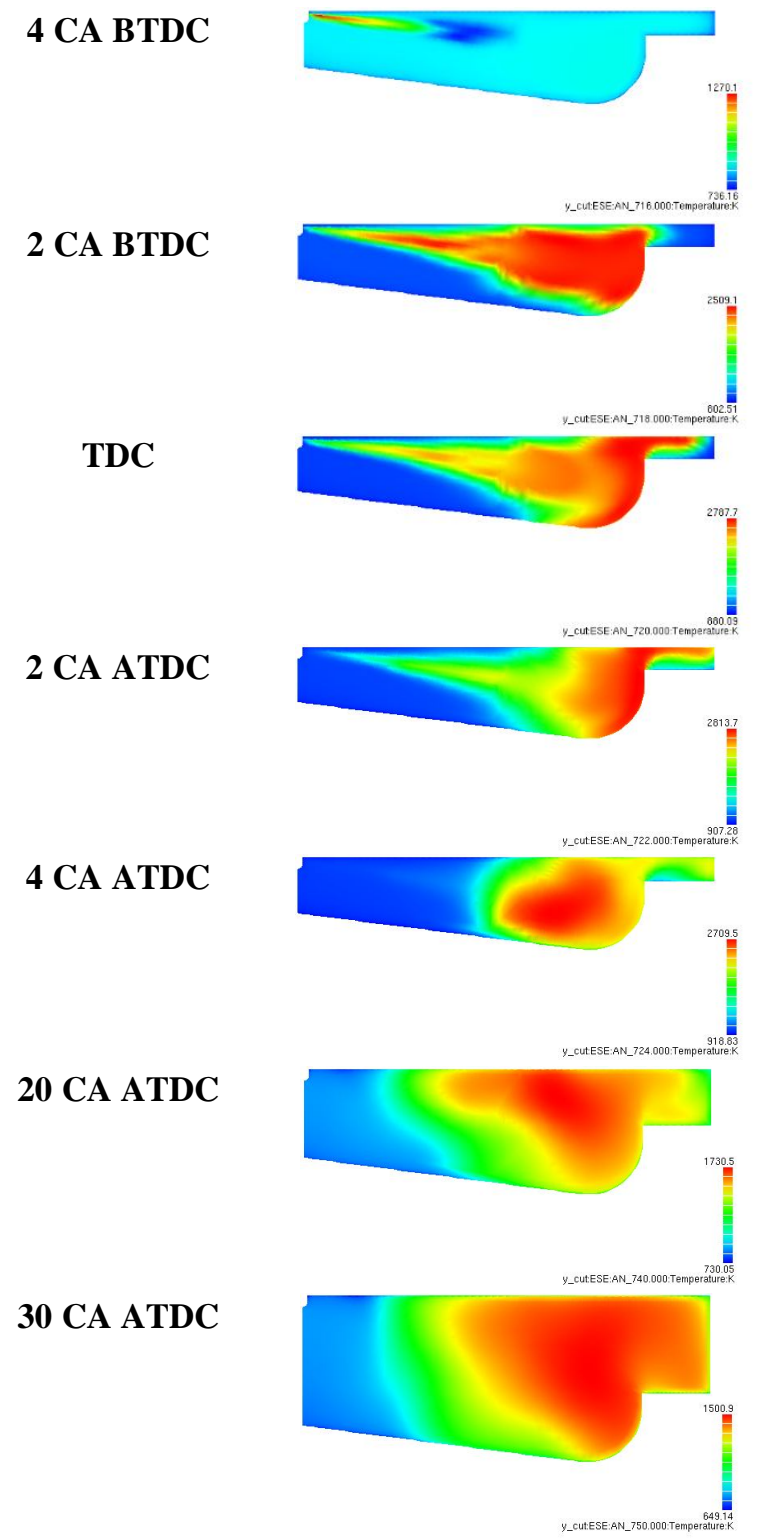

Figure 6: Changing the temperature field in the cylinder (fuel injection advance angle 5 CA BTDC, boost pressure of 0.15 $\left.\mathrm{MPa}, d_{c}=0.1 \mathrm{~mm}\right)$ 


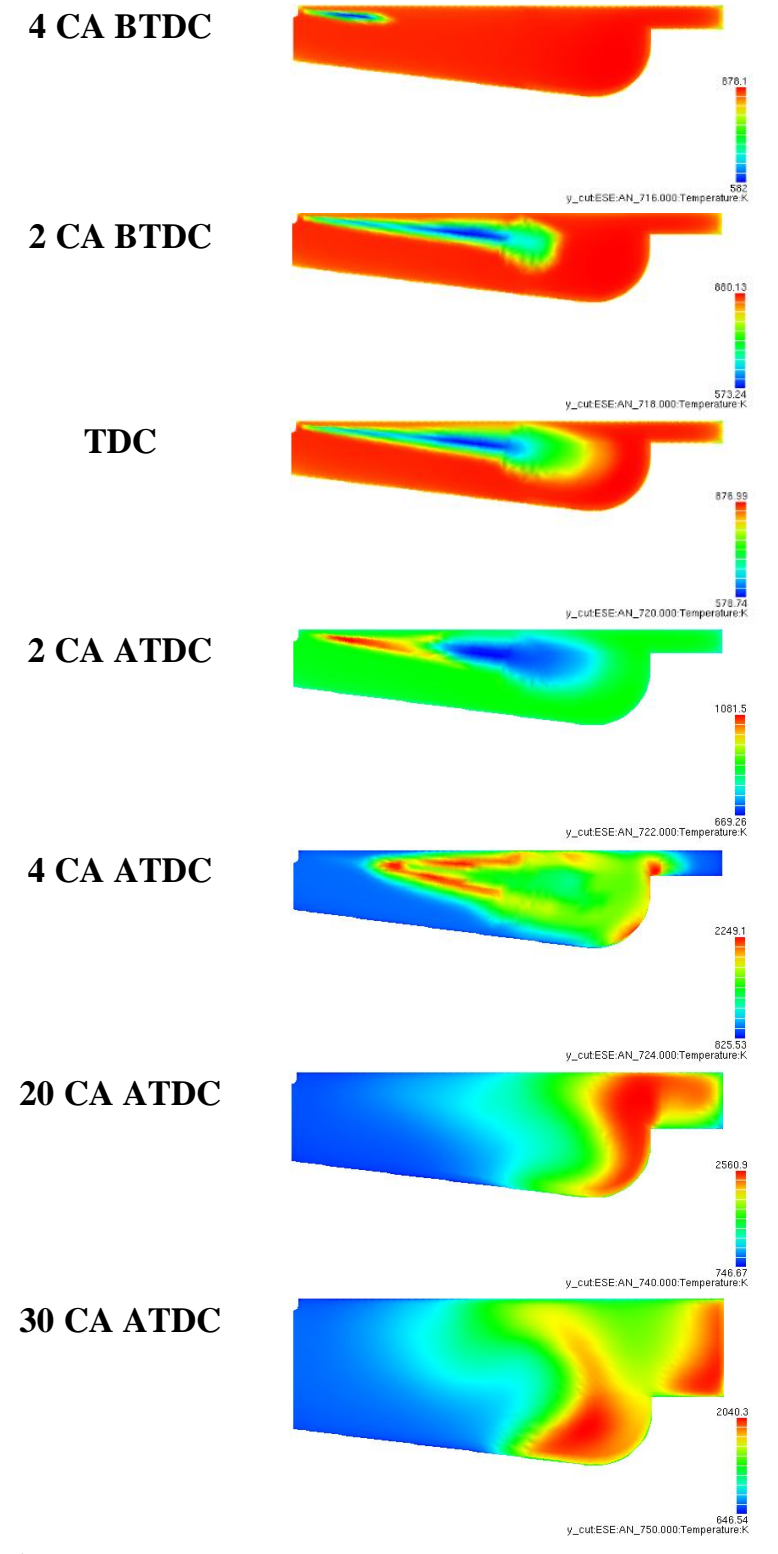

Figure 7: Changing the temperature field in the cylinder (fuel injection advance angle 5 CA BTDC, boost pressure of 0.15 $\left.\mathrm{MPa}, d_{c}=0.24 \mathrm{~mm}\right)$

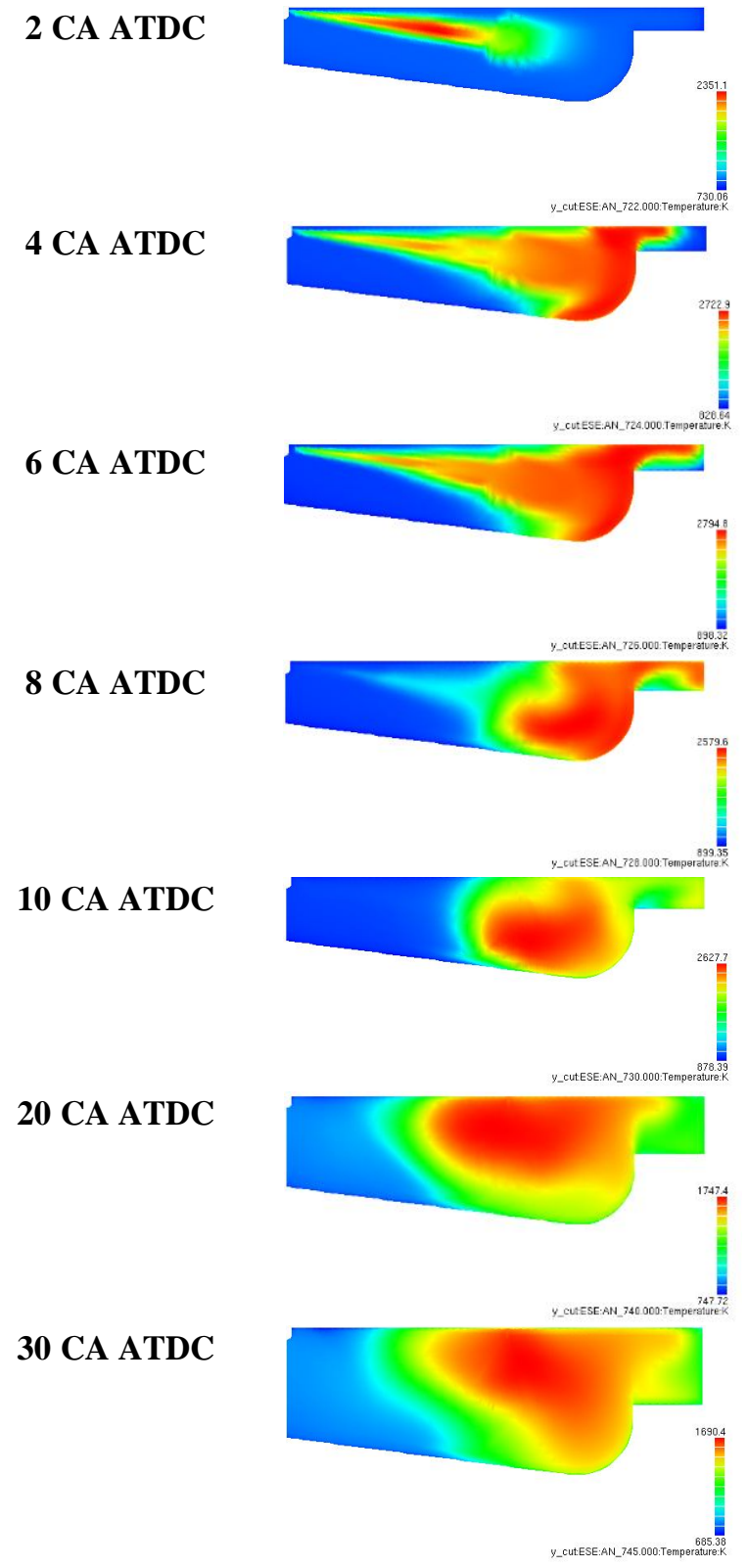

Figure 8: Changing the temperature field in the cylinder (start of fuel injection at TDC, boost pressure of $0.15 \mathrm{MPa}$, $\left.d_{c}=0.1 \mathrm{~mm}\right)$ 


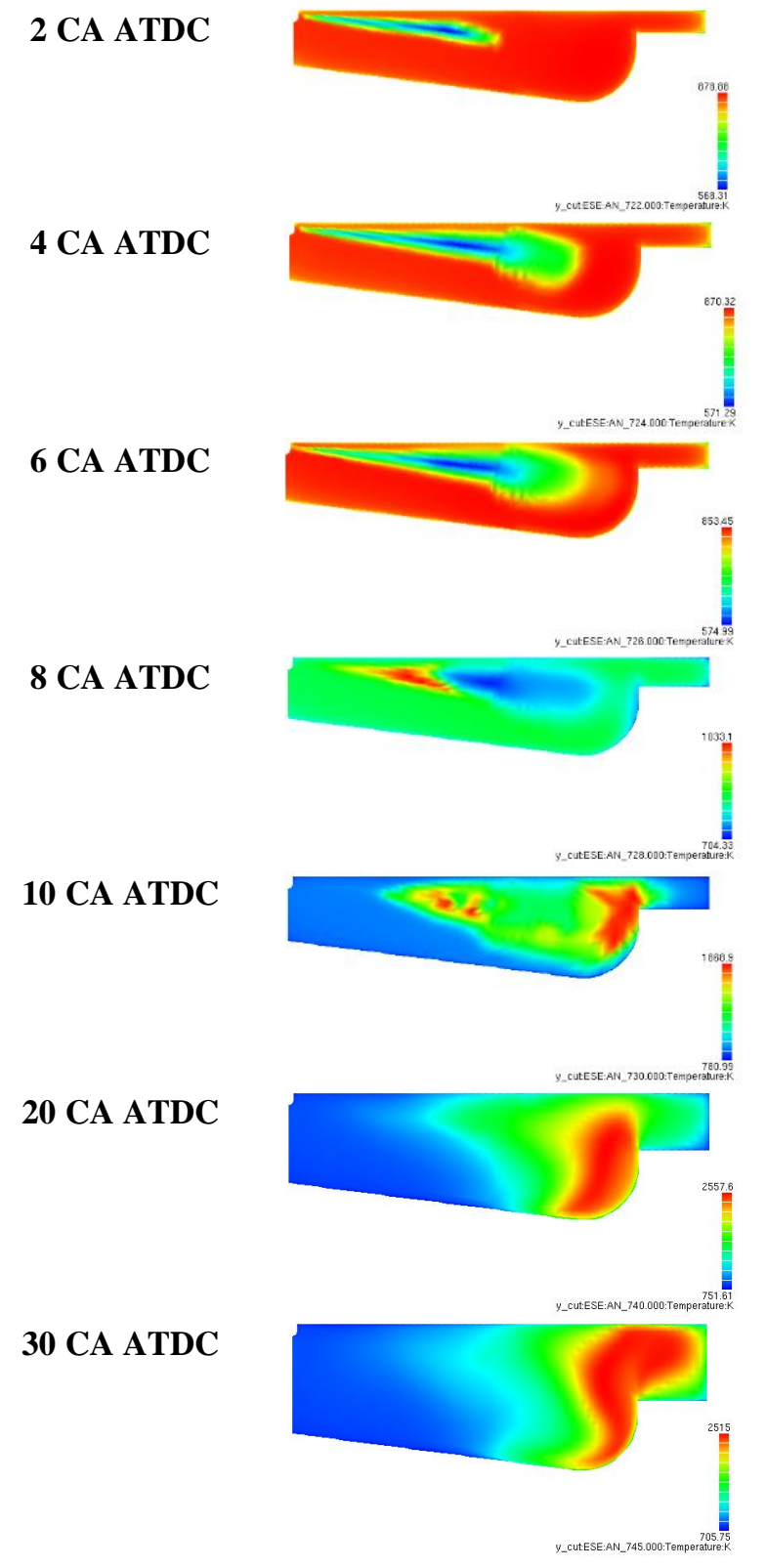

Figure 9: Changing the temperature field in the cylinder (start of fuel injection at TDC, boost pressure of $0.15 \mathrm{MPa}$,

$$
d_{c}=0.24 \mathrm{~mm} \text { ) }
$$

From Figure 6, Figure 7 and Figure 8, Figure 9, it can be seen that with $d_{c}=0.1 \mathrm{~mm}$, combustion occurs at $2 \mathrm{CA}$ from the moment of fuel supply. The combustion process is very fast and the combustion zone comprises almost the entire combustion chamber.

The results of changing the indicator power $\left(N_{i}\right)$ and break specific fuel consumption $\left(g_{e}\right)$ as $d_{c}$ increases are shown in Figure 10.
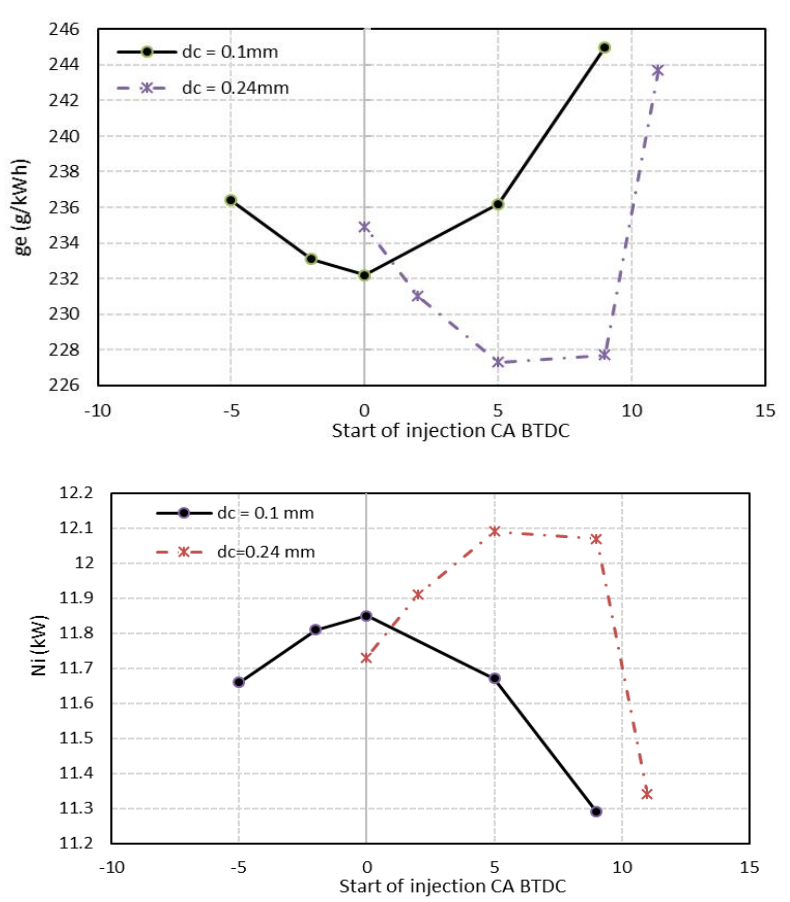

Figure 10: The results of changing the indicator power $\left(N_{i}\right)$ and break specific fuel consumption $\left(g_{e}\right)$ as $d_{c}$ increases (boost pressure of $0.15 \mathrm{MPa}$ )

With the same amount of fuel per cycle, when using $d_{c}=0.24$ $\mathrm{mm}$, the lowest break specific fuel consumption is 227.3 $\mathrm{g} / \mathrm{kWh}$, and the maximum indicator power reaches $12.09 \mathrm{~kW}$ when fuel injection advance angle is 5 CA BTDC. With $d_{c}=$ $0.1 \mathrm{~mm}$ and fuel injection advance angle is TDC, the engine has the lowest $g_{e}$ and maximum $N_{i}$. The minimum break specific fuel consumption is increased by $2.2 \%$, and the maximum indicator power is reduced by $1.99 \%$ when compared between $d_{c}=0.1 \mathrm{~mm}$ and $d_{c}=0.24 \mathrm{~mm}$.

The change in emissions of toxic components in engine exhaust gases is shown in Figure 11. From the results presented, it can be seen that reducing the diameter led to an increase in $\mathrm{NO}_{\mathrm{x}}$ and soot emissions. At the same time, $\mathrm{CO}$ and $\mathrm{HC}$ emissions are decreasing.

With a decrease in the nozzle diameter, the quality of mixture formation and combustion has improved, and combustion temperatures have increased. At the same time, under conditions of high temperature and an increase in the contact area between fuel and oxygen, the area of the combustion process increases, causing an increase in the amount of $\mathrm{NO}_{\mathrm{x}}$.

$\mathrm{NO}_{\mathrm{x}}$ emissions decrease when fuel is injected near or after the TDC, while soot emissions increase. It can be seen that in order to reduce $\mathrm{NO}_{\mathrm{x}}$ emissions, it is necessary to inject the fuel later using $d_{c}=0.1 \mathrm{~mm}$. It is also possible to use multiple injections to reduce the temperature in the combustion chamber, which helps to reduce $\mathrm{NO}_{\mathrm{x}}$ emissions. 

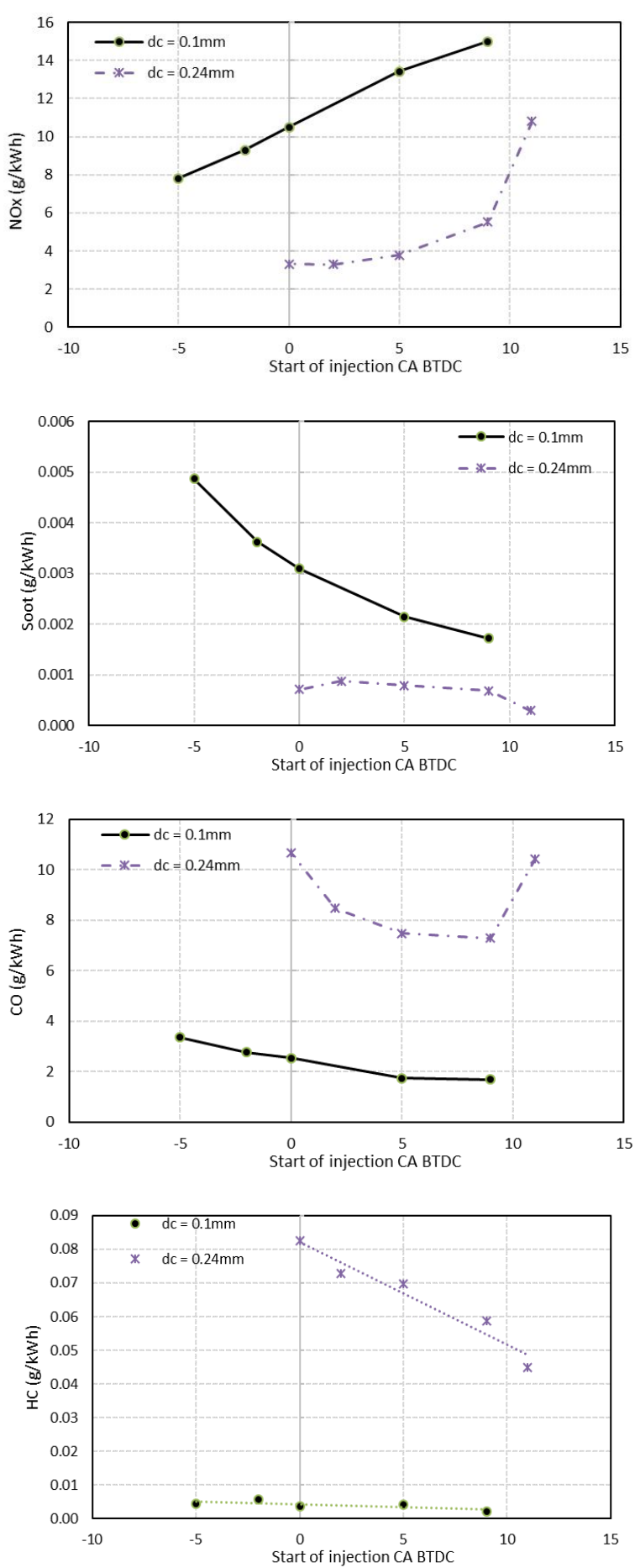

Figure 11: Comparison of exhaust emissions of a diesel engine as $d_{c}$ increases (boost pressure of $0.15 \mathrm{MPa}$ )

$\mathrm{HC}$ and $\mathrm{CO}$ emissions decrease as the diameter decreases. If $d_{c}$ is large, the incompleteness of fuel combustion increases. Therefore, increase the amount of $\mathrm{CO}$ and $\mathrm{HC}$ emissions. With $d_{c}=0.1 \mathrm{~mm}, \mathrm{HC}$ is almost zero.

\section{CONCLUSION}

In this study, a mathematical model of a single-cylinder engine was built using AVL Fire software. The results show the effect of the diameter $\left(d_{c}\right)$ of the nozzle hole on engine performance. Should be noted:

- with the same amount of fuel injection, with an increase in $d_{c}$, less fuel injection pressure is required;

- with the same amount of fuel that is fed into the cycle and $d_{c}=0.1 \mathrm{~mm}$, the engine heat release rate is 3 times lower than when $d_{c}=0.24 \mathrm{~mm}$;

- reducing the diameter of the spray hole leads to a decrease in engine power and an increase in the break specific fuel consumption;

- $\mathrm{NO}_{\mathrm{x}}$ emissions are reduced when the injection advance angle is close or after TDC;

- if $d_{c}$ is large, the incompleteness of fuel combustion increases;

- with $d_{c}=0.1 \mathrm{~mm}$, combustion occurs better with a larger combustion area. However, the combustion area is close to the wall of the combustion chamber, so soot emissions increase.

\section{ACKNOWLEDGEMENT}

This work was supported by the Russian Science Foundation [grant number 19-19-00598]. Site: https://www.rscf.ru/

\section{REFERENCES}

1. M. G. Shatrov, V. V. Sinyavski, A. Y. Dunin, I. G. Shishlov, A. V. Vakulenko. Method of conversion of high- and middle-speed diesel engines into gas diesel engines, Facta Universitatis. Series: Mechanical Engineering, 2017, Vol. 15, No 3 pp. 383-395, DOI: 10.22190/FUME171004023S.

2. M. G. Shatrov, V. V. Sinyavski, A. Yu. Dunin, I. G. Shishlov, A. V. Vakulenko, A. L. Yakovenko. Using simulation for development of the systems of automobile gas diesel engine and its operation control, International Journal of Engineering and Technology, 2018, №7 (2.28), pp. 288-295. https://doi.org/10.14419/ijet.v7i2.28.12947

3. V. V. Sinyavski, M. G. Shatrov, A. Y. Dunin, I. G. Shishlov, A. V. Vakulenko. Results of simulation and experimental research of automobile gas diesel engine, Periodicals of Engineering and Natural Sciences, 2019, Vol. 7, No. 1, pp. 281-286. https://doi.org/10.21533/pen.v7i1.396

4. V. V. Sinyayski, M. G. Shatrov, A. Y. Dunin, I. G. Shishlov, A. V. Vakulenko. Results of simulation and 
Andrey Y. Dunin et al., International Journal of Emerging Trends in Engineering Research, 8(6), June 2020, 2301 - 2308

experimental research of automobile gas diesel engine, 2019 systems of signals generating and processing in the field of on board communications. Proceedings Paper, 2019, C. 8706756.;

DOI: $10.1109 /$ SOSG.2019.8706756.

5. A. L. Iakovenko, A. Y. Dunin, P. V. Dushkin, E. A. Savastenko, M. G. Shatrov. The influence of mass composition of water-fuel emulsion on ecological characteristics of a diesel engine, Energies, 2019, Volume 12, Issue 14, pp. 2689; DOI:10.3390/EN12142689.

6. Engine Emission Control Retrieved from: https://www.dieselnet.com/tech/engine_emission-contro 1.php

7. M. G. Shatrov, V. I. Malchuk, A. U. Dunin, A. L. Yakovenko. The influence of location of input edges of injection holes on hydraulic characteristics of injector the diesel fuel system, International Journal of Applied Engineering Research, 2016, Volume 11, Number 20, pp. 10267-10273.

8. M. G. Shatrov, V. I. Malchuk, A. Y. Dunin, I. G. Shishlov, V. V. Sinyavski. A control method of fuel distribution by combustion chamber zones and its dependence on injection conditions, Thermal Science, 2018, Volume 22, Number 5, pp. 1425-1434, DOI: 10.2298/TSCI18S5425S.

9. M. G. Shatrov, V. I. Malchuk, S. D. Skorodelov, A. Y. Dunin, V. V. Sinyavski, A. L. Yakovenko. Simulation of fuel injection through a nozzle having different position of the spray holes, Periodicals of Engineering and Natural Sciences, 2019, Vol. 7, No. 1, pp. 458-464.

10. M. G. Shatrov, L. N. Golubkov, A. U. Dunin, A. L. Yakovenko, P. V. Dushkin. Influence of high injection pressure on fuel injection perfomances and diesel engine worcking process, Thermal Science, 2015, Volume 19, Number 6, pp. 2245-2253, DOI: 10.2298/TSCI151109192S.

11. M. G. Shatrov, L. N. Golubkov, A. U. Dunin, A. L. Yakovenko, P. V. Dushkin. Research of the injection pressure 2000 bar and more on diesel engine parameters, International Journal of Applied Research, 2015, Volume 10, Number 20, pp. 41098-41102.

12. M. G. Shatrov, L. N. Golubkov, A. Yu. Dunin, P. V. Dushkin, A. L. Yakovenko. A method of control of injection rate shape by acting upon electromagnetic control valve of common rail injector, International Journal of Mechanical Engineering and Technology, 2017, Volume 8, Issue 11, pp. 676-690.

13. M. G. Shatrov, L. N. Golubkov, A. U. Dunin, P. V. Dushkin, A. L. Yakovenko The new generation of common rail fuel injection system for Russian locomotive diesel engines, Pollution Research, 2017, Volume 36 (3), pp. 678-684.

14. M. G. Shatrov, L. N. Golubkov, A. U. Dunin, A. L. Yakovenko, P. V. Dushkin. Experimental research of hydrodynamic effects in common rail fuel system in case of multiple injection, International Journal of
Applied Engineering Research, 2016, Volume 11, Number 10, pp. 6949-6953.

15. M. G. Shatrov, L. N. Golubkov, A. Y. Dunin, P. V. Dushkin. Pressure oscillations as a factor affecting the management of the fuel injection process in the combustion chamber of a diesel engine, 2019 systems of signals generating and processing in the field of on board communications. Proceedings Paper, 2019, C. 8706808.; DOI: 10.1109/SOSG.2019.8706808.

16. J. E. Johnson, H. Y. Seung, J. D. Naber, S.-Y. Lee, G. Hunter, R. Truemner, T. Harcombe Characteristics of 3000 bar diesel spray injection under non-vaporizing and vaporizing conditions, ICLASS 2012, 12th Triennial International Conference on Liquid Atomization and Spray Systems, 2012.

17. AVL-FIRE User Guides, v2014.

18. K. Hanjalic, M. Popovac, M. Hadziabdic. A robust near-wall elliptic-relaxation eddy-viscosity turbulence model for CFD, International Journal of Heat and Fluid Flow, 2004, Vol. 25, pp. 1047-1051. https://doi.org/10.1016/j.ijheatfluidflow.2004.07.005 